\title{
Calidad de la representación política y desafíos de la LXIII Legislatura de la Cámara de Diputados en México*
}

Quality of political representation and challenges of the sixty-third Legislature of the Chamber of Deputies of Mexico

Qualidade da representação política e desafios da LXIII Legislatura da Câmara de Deputados no México

Recibido el 17 de septiembre de 2015. Aceptado el 5 de noviembre de 2015

Alicia Hernández de Gante**

México

Para citar este artículo:

Hernández de Gante, Alicia (diciembre, 2015). Calidad de

la representación política y desafíos de la LXIII Legislatura de la Cámara de Diputados en

México. Ánfora, 22(39), 169-

201. Universidad Autónoma de

Manizales. ISSN 0121-6538.

\section{Resumen}

Objetivo: identificar los fenómenos que afectan la calidad de la representación política y determinar los desafíos que enfrentarán los partidos políticos y los representantes en la rendición de cuentas y en la transparencia de sus acciones. Metodología: investigación documental, enfoque deductivo; su universo de estudio fue la Cámara de Diputados de México en la LXIII Legislatura (2015-2018). Para analizar las diferentes dimensiones del problema se recurrió a teorías de la sociología política con el fin de conceptualizar el eje del tema-problema, la representación política, así como para saber cómo se articulan una serie de procesos sociales que permiten su sentido en la actividad política en la relación

\footnotetext{
* Artículo derivado del proyecto colectivo Sociedad, Estado y sus actores políticos en México y América Latina, de la Red de Cuerpos Académicos Sociedad y Política

** Doctora en Sociología. Profesora de la Benemérita Universidad Autónoma de Puebla, México. Correo electrónico: aliciahdegante@gmail.com
} 
representante-representados. Se analizaron algunos puntos donde la representación se problematiza mostrando el malestar de la sociedad civil y un historial de descrédito de las instituciones representativas. Resultados: se encontró que existe desconocimiento de la ciudadanía sobre quiénes son sus representantes de la LXIII Legislatura; también se evidenciaron indicadores de poca eficacia del trabajo legislativo, lo que plantea la necesidad de acciones de la sociedad civil y de autoridades para el cumplimiento en la rendición de cuentas. Conclusiones: el ideal democrático de la buena calidad de la representación política constituye el principal desafío de los actuales diputados, que se logrará con una transparente rendición de cuentas hacia los representados y la ciudadanía.

Palabras clave: Representación política, Calidad, Sociedad civil, Malestar, Rendición de cuentas

\section{Abstract}

Objective: to identify the phenomena that affect the quality of political representation and determine the challenges that political parties and representatives will face to account for their actions and transparency. Methodology: desk -based research and deductive approach. The research was conducted on the Chamber of Deputies of Mexico in the sixty-third Legislature (2015-2018). Different dimensions of the problem were analyzed according to theories of political sociology in order to conceptualize political representation as the axis of the problem, and to find out how social processes are linked to give meaning to the political activity in relation to representatives and citizens. Some of the aspects of the representation became problematic by the discomfort of civil society and a history of discredited representative institutions were analyzed. Results: it was found that there is lack of knowledge about the representatives of the sixty-third Legislature and no indicators of effectiveness of legislative work were showed. It suggests the need of actions by civil society and authorities for accountability. Conclusions: the democratic ideal of good quality of political representation is the main challenge to current deputies. It will be achieved with a transparent accountability to citizens.

Keywords: Political representation, Quality, Civil society, Discomfort, Accountability 


\section{Resumo}

Objetivo: identificar os fenômenos que afeitam a qualidade da representação política e determinar os desafios que enfrentarão os partidos políticos e os representantes na rendição de contas e na transparência de suas ações. Metodologia: pesquisa documental, enfoque dedutivo; seu universo de estudo foi a Câmara de Deputados do México na LXIII Legislatura (2015-2018). Para analisar as diferentes dimensões do problema se acudiu a teorias da sociologia política com o proposito de conceituar o eixo do tema-problema, a representação política, assim como para saber como se articulam uma série de processos sociais que permitem seu sentido na atividade política na relação representante-representados. Analisaram-se alguns pontos onde a representação se problematiza mostrando o incômodo da sociedade civil e um historial de descrédito das instituições representativas. Resultados: encontrou-se que existe desconhecimento da cidadania sobre quem são seus representantes da LXIII Legislatura; também se evidenciaram indicadores de pouca eficácia do trabalho legislativo, o que apresenta a necessidade de ações da sociedade civil e de autoridades para o cumprimento na rendição de contas. Conclusões: o ideal democrático da boa qualidade da representação política constitui o principal desafio dos atuais deputados, que se logrará com uma transparente rendição de contas para os representados e a cidadania.

Palavras chave: Representação política, Qualidade, Sociedade civil, Incômodo, Rendição de contas. 


\section{Introducción}

En las elecciones federales de 2015, México ha vivido un episodio trascendental para su democracia. Fue un proceso electoral, digno de análisis por todos los cambios y acontecimientos suscitados en el marco de la reforma político electoral de 2013, del nuevo Instituto Nacional Electoral (INE) y de la nueva figura jurídico-electoral de los candidatos independientes. Hablar de los procesos electorales implica considerar varios factores y un sinnúmero de actores que se sintetizan en dos sujetos colectivos: representantes y representados; sujetos que se vinculan por una mediación institucional llamada representación política.

Los antecedentes sobre la exigencia de la sociedad civil de saber quiénes son sus representantes en el Congreso de la Unión, es relativamente reciente. Durante las siete décadas continuas que permaneció el Partido Revolucionario Institucional (PRI) al frente de la presidencia de la república (1928-2000), éste consintió que fuera casi incuestionable su desempeño político y legislativo. El partido mayoritario del Congreso era el partido político del presidente. A raíz de la alternancia partidista en la presidencia en el 2000 con Vicente Fox del Partido Acción Nacional (PAN), emerge a la opinión pública la actuación de ambas Cámaras del Congreso. Dos factores lo determinan: a) ningún partido logró contar con mayoría, la pluralidad partidista obligó a los actores no sólo a negociar para lograr acuerdos, sino a la exhibición pública del adversario político; b) con el priísmo las iniciativas presidenciales enviadas al Congreso tenían una eficacia propositiva mayor al 97\%, con el expresidente Fox se reducen en la LVIII Legislatura de la Cámara de Diputados a un promedio de $84.4 \%$, debido a la nueva composición partidista, demandando mayor esfuerzo de negociación por parte del ejecutivo (Cepeda, 2004).

Este primer escenario de pluralidad política acentúa desavenencias y confrontaciones entre los poderes y actores confrontando al ejecutivo con el legislativo respecto a la agenda política nacional; hechos que son ventilados por la campaña de desprestigio que emprendió Fox hacia el Congreso en los medios de comunicación masiva (Flores, 2004) formando opinión pública negativa. Actualmente, otras son las condiciones, pero la suma de otros factores no aminora la percepción negativa hacia los diputados con una confianza menor al 20\% (IFE, 2014). 
En cambio, los análisis sobre el Congreso de la Unión en México han proliferado. La propia institución tiene centros de estudios ${ }^{1}$ que nutren de información para el trabajo legislativo. Los espacios académicos realizan investigación en torno a temas cruciales: su historia (Camacho, 2006) y funcionamiento (Pérez y Martínez, 2000); su representación política (Béjar, 2006; Hernández, 2008); las coaliciones y producción legislativa (Gimate-Welsh y Rodríguez, 2008, 2015); su importancia para la democracia (Valencia, 2007; Alcántara y Hernández, 2009); o sobre el quehacer legislativo (Díaz, 2006; Béjar, 2009); siendo tema más reciente la reelección de los diputados (Dworak, 2003; Tuckman, 2013) figura aprobada en la reforma política-electoral de 2013 que se aplicará en las elecciones de 2018.

Los datos que forman opinión pública sobre los representantes, los generan las empresas encuestadoras especialistas, particularmente en tiempos de procesos electorales. Éstas, así como los medios de comunicación masiva, sobre todo el periodismo de investigación, constituyen la vía de conocimiento hacia los integrantes del Congreso de la Unión, pero más allá de los intereses investigativos señalados, la ciudadanía poco sabe del quehacer de sus legisladores, a no ser cuándo se hace patente la sospecha o comprobación de actos fuera de la ley por la autoridad o por sus opositores políticos.

En esta perspectiva los campos temáticos que se analizan en este trabajo giran en torno a la representación política, a sus componentes esenciales representantes-representados- y a ciertos fenómenos que afectan la calidad en la acción política de representar. La calidad se entiende como la actuación sustantiva o responsiva (responsiveness) de los representantes hacia sus representados, que debe sustentarse en la congruencia de acciones de los primeros hacia los intereses de los segundos (Pitkin, 1985) particularmente, en su acción sustantiva de creación de leyes y preferencia de ciudadanos (Mainwaring, 2008). La acción sustantiva por otros también exige el conocimiento y la explicación sobre quiénes son los representantes, qué hacen y cómo lo hacen tanto en los ámbitos sustantivos como en los institucionales ${ }^{2}$, a fin de que los ciudadanos

1. La Cámara de Diputados tiene 5 Centros de Estudios: Centro de Estudios de Finanzas Pública (CEFP); Centro de Estudios de Derecho e Investigaciones Parlamentarias (CEDIP); Centro de Estudios para el Desarrollo Rural Sustentable y la Soberanía Alimentaria (CEDRSSA); Centro de Estudios para el Adelanto de las Mujeres y la Equidad de Género (CEAMEG); Centro de Estudios Sociales y de Opinión Pública (CESOP).

2. Otros estudios consideran que la calidad de la representación política se mide en función de los sistemas electorales, del sistema de partidos y de la sociedad civil; puntos con los que coincide el presente estudio (Levine y Molina, 2007; Gilas, 2010), pero se alude a la sociedad civil y a la relación representadosrepresentantes desde una perspectiva de la sociología política. 
ejerzan accountability vertical, premiando o castigando con su voto a los futuros representantes (O’Donnell, 2007; Novaro, 2000).

Para analizar las diferentes dimensiones del problema de la calidad de la representación política es necesario tener un sustento teórico que aclare y guíe sobre las categorías que la conforman. Así, la estructura de esta investigación parte de la revisión teórica sobre ¿qué es la representación política? con la finalidad de tener presente esta figura jurídica esencial de nuestras democracias modernas y representativas. A ella se vinculan de forma sistematizada otros componentes de los cuales sólo se analiza la relación del binomio representantes y representados y algunos puntos donde la representación se tensiona -crisis en los partidos políticos, en la credibilidad institucional y en los representantesque evidencia el malestar de la sociedad civil, como se muestra a continuación.

\section{Un acercamiento a la representación política}

Tratar de definir qué es la representación es complejo. La acción de representar se aplica a un extenso campo de la actividad humana. Cuando la representación se formaliza se puede considerar el modo en que actúan las personas que realizan la representación: actuar en su nombre, en su interés, con su autoridad o en su beneficio (Pitkin, 1985). La acción de representar la pueden realizar múltiples sujetos: legisladores, embajadores, comisionados, apoderados, tutores, y un largo etcétera. En esta amplia perspectiva se puede afirmar que todos podemos representar, y por tanto, todo es representable, y aún más, todos deseamos ser representados en diferentes circunstancias.

Es entendible que también en la ciencia política se presente el problema con relación no sólo al idioma, sino y de forma particular en su aplicación e interpretación de la familia de palabras represent (Bobbio, 1998). El asunto muestra parte de su complejidad cuando utilizamos las palabras relacionadas con representación, representatividad, representativo o tratamos de entablar la relación entre los representantes y sus representados. Las democracias modernas se mueven en el amplio campo de la representación política, es su parte sustantiva y no sería posible concebirla sin el componente representativo electoral. Ella se constituyó en el gran descubrimiento para gobernar, sobre ella emergen los pilares de la democratización y de la liberalización que posibilita a la ciudadanía ejercer sus derechos políticos ya sea votando y eligiendo o siendo partícipe del gobierno, ambos en la plena capacidad del ejercicio de representación (Dahl, 1989). 
Por lo tanto, el concepto representación puede ser entendido de diferentes maneras. De forma global, pero singularizando en una persona, un presidente o un primer ministro representa a un pueblo, a una nación y a una comunidad política ampliamente organizada como sería un Estado. Con relación a los cuerpos colegiados los parlamentos y los congresos tiene la función de generar representatividad de la ciudadanía en su composición plural y democrática. Por su parte, la relación intersubjetiva o existencial entre los representantes y los representados, implica que la representación política cree relaciones de identidad y de construcción simbólica como producción social.

\section{El binomio de la representación política}

Analicemos ahora a los dos componentes claves que requiere la acción de la representación política: representantes y representados pero considerando que interpretar el papel de estos dos sujetos colectivos debe enmarcarse en las diferentes perspectivas que determinan las teorías que explican a la democracia. No es parte de este trabajo entrar en ese debate, pero tratando de darle un enfoque teórico para comprender el importante papel que tienen en los procesos electorales retomamos algunas ideas de la democracia procedimentalista (sustentada en el constitucionalismo positivista) ya que supone a la representación como el mecanismo que da legitimidad a los gobernantes electos directamente por los ciudadanos. Se sobreentiende que la representación política y los mecanismos jurídicos que deriven se sujetan a procedimientos institucionales. En este sentido, la democracia representativa tendría exclusivamente un objetivo: que el candidato gane las elecciones con base a los procedimientos establecidos en las legislaciones electorales, es decir, el candidato, más tarde elegido y vuelto representante, actuó por motivaciones exclusivamente electorales en el entendido que los partidos políticos y los políticos están y existen para ganar votos (Sánchez, 2010).

Tradicionalmente, la acción política recae en el representante, en aquel que toma las decisiones, y en la actitud un tanto pasiva del representado. El sentido común indica que la acción política del representado termina al emitir su voto y que, de acuerdo al principio del mandato no vinculado que caracteriza a nuestros gobiernos representativos, la relación entre ambos ha concluido puesto que, de allí en adelante, el representante es quien realizará propiamente la acción política.

No obstante, la cuestión no es tan sencilla. A pesar de que los ciudadanos son los que han elegido debemos tomar en cuenta ciertas implicaciones de los 
representados. Si en apariencia termina su labor al emitir el voto, y ya no hacen política, realmente las actitudes "pasivas" tienen consecuencias: los votantes, los ciudadanos en la vida política cotidiana observan, juzgan, opinan, votan y demandan (Novaro, 2000). La forma en que los representados influyen en la política pública es por medio del juicio retrospectivo, es decir, al emitir un nuevo voto evalúan las acciones pasadas del representante y/o de su partido político, teniendo en sus manos la fuerza de apoyar o rechazar al nuevo candidato.

Desde cualquier teoría de la democracia esto sería loable. Pero este ideal de la democracia moderna no es fácil de sostener puesto que esta explicación implica que la mayoría de los representados posean una serie de elementos como conciencia cívica, interés en la vida política, simpatía partidista y juicio crítico, condiciones que desafortunadamente dada su ausencia han mostrado otras caras de la democracia como es crisis de la participación política, en parte debido al descrédito de ciertas instituciones ligadas a la democracia.

\section{Malestar ante la representación política}

Partimos de la percepción, al menos en México, de que la representación cumple escasamente las tradicionales funciones que se le adjudican en las sociedades políticas contemporáneas: reclutamiento selectivo y benéfico de la clase política para fungir como representantes; apropiada canalización de demandas de la sociedad civil en general mediante iniciativas y nuevas legislaciones; generación de espacios de legalidad y legitimidad para las acciones políticas del gobierno en ejercicio; y mecanismos de mediaciones institucionales a través de los partidos y los representantes entre la sociedad y el Estado (Hernández, 2008). Existe una latente tensión entre los representantes y los representados.

En los espacios de la democracia todos deseamos ser representados pero, ¿qué se representa de los representados? Esta interrogante se dificulta aún más si consideramos que un representante en el Congreso representa miles de representados, y se espera que el representante tenga la suficiente sensibilidad y capacidad para captar los intereses de los representados. Sumamos que el representante, más que representar a los representados en particular, representa a la nación, lo que puede significar una postura endeble para los representados. Ante ello, autores como Novaro (2000) critican la constante separación, e incluso, en una posición extrema considera que los ciudadanos dejarán de ser representados para ser sólo gobernados. Al respecto, los fenómenos que brevemente analizamos a continuación han sido sumamente debatido y reconocidos como puntos de quiebre para la calidad de la representación política provocando malestar en la sociedad civil. 


\subsection{Crisis de los partidos políticos}

Los primeros actores de la democracia representativa han estando en permanente cuestionamiento, paradójicamente, éste se agudiza, en tanto se generan espacios de liberalización y democratización en los procesos electorales. En México, su historia ha ido a la par de esos procesos. La apertura e inclusión de nuevas entidades partidistas efectivamente implican pasos hacia la consolidación de la democracia, no obstante, han estado muy lejos de cubrir las expectativas del electorado particularmente por las alianzas con fines electorales que han desdibujado las identidades ideológicas de los partidos: derecha, centro e izquierda, así como por los partidos "satélites" que sin miramiento alguno se suman a los partidos mayoritarios. Más allá de los intereses de ganar elecciones, su funcionamiento interno, particularmente su falta de democracia, que se traduce en un claro déficit del propio proceso democrático, contribuye a su deslegitimación, hechos que se han llevado al Tribunal Electoral del Poder Judicial de la Federación (TEPJF) ventilando claras disputas de grupos de poder internos (Albala, 2014; Gómez, 2011). A ello se suman acciones sumamente graves como la sospecha de vinculación de miembros de los tres principales partidos con grupos de la delincuencia organizada (Reforma, 23 de agosto, 2015) poniendo en tela de juicio el mandato representativo.

\subsection{Crisis de credibilidad institucional}

El problema de la credibilidad institucional y de la certeza de sentirse representado se hace patente en México si consideramos el sistema de partidos y la institución parlamentaria: el Congreso de la Unión. Desde un panorama general y siguiendo a Santamaría (1998), partamos del hecho de que los diputados son representantes de la nación y que ésta se constituye en asamblea para ejercer su soberanía, es decir, el parlamento como institución representativa es la encargada de canalizar la voluntad popular a través de los representantes y de crear las normas que protejan jurídicamente las obligaciones, derechos y libertades de los individuos. Se espera que en el Congreso la pluralidad de opiniones esté representada, que los conflictos políticos se expresen pacíficamente, que la oposición asuma las normas institucionales de competencia contribuyendo a los procesos de democratización, y que emerja como el espacio institucional de la representación. Más aún, se espera que el Congreso, en el plano simbólico, sea la negación de un régimen autoritario y el momento constitutivo de la democracia; que sea el espacio en el que las fuerzas políticas construyan las bases del consenso constitucional y que sea el ámbito no sólo donde los partidos y sus líderes asienten su legitimidad sino el espacio donde la legalidad y la legitimidad 
democrática se conjuguen (Santamaría, 1998). Sin embargo, en México, por más de siete décadas (antes de la alternancia) se hizo patente la debilidad del Poder Legislativo ante el Poder Ejecutivo, en detrimento de la calidad de la representación política.

\subsection{Crisis de los representantes}

La pluralidad y participación como características intrínsecas de la democracia toma otras formas. La tradicional figura de los representantes ha cambiado. En México, por décadas, ésta se ligó a la profesión de la abogacía. Actualmente, cuando los representantes tienen algún título universitario éste se amplía con diversas profesiones, o cuando carecen de él, entran en el juego político, otras ocupaciones ajenas a la arena política (véase tabla 3). En franca rebeldía, inconformidad y malestar los ciudadanos en respuesta proponen, eligen o parodian a los representantes, es decir, existe un quiebre de representantes tradicionales por representantes posmodernos, algunos de ellos ligados a actividades deportivas, del cine-tv o de labores del hogar, e incluso en el imaginario popular sustitución de candidatos por animales; un ejemplo: "El gato morris" (candiGato para alcalde por Xalapa para el periodo 2014-2017) cuya exitosa campaña en redes sociales hizo alusión al descontento y rechazo a la clase política. La crisis de la figura de los representantes se va mostrando conforme avanzan los procesos de democratización. Los actores activos, llámense representantes populares, y los actores en apariencia pasivos, electores, se distancian a la par que aparecen nuevos escenarios y nuevas acciones: violencia, guerra sucia, venta fácil del voto y corrupción del voto cívico. Tenemos también la despolitización de la vida pública: parte del malestar de la sociedad civil hacia la representación se encuentra en la actitud de los políticos, los representantes que incumplen promesas de campaña o que actúan conforme intereses particulares o que incurren en actos de corrupción o falta de responsabilidad, traicionando el mandato representativo. Franzé (1996), interpreta al discurso del malestar de la sociedad civil como crisis de lo político, en tanto que la política también en crisis, fracasa en su acercamiento a la ciudadanía: rechazan al político profesional por el independiente, cuestionan los grandes financiamientos públicos, e identifican al aparato partidario como centro de operaciones de política corrupta. En otras latitudes, por ejemplo, en Colombia, el desencanto político se debe a: "el sistema electoral que estimula la dispersión y el régimen presidencialista que tiende a dejar sin funciones al congreso o a chocar con éste” (Pardo, 2008:4).

Ahora bien, cabe preguntarse si esa pluralidad de actores y de acciones en los procesos electorales ¿desvirtúan o enriquecen la democracia? ¿mejoran la calidad de la representación política? Parte de las respuestas las reflexiona Abal, quien afirma que la principal causa de estos fenómenos es la pérdida de credibilidad de la metanarración 
representativa. El orden político tuvo en su momento narraciones emancipatorias míticas de legitimación: "Asistimos a su progresivo debilitamiento como ficción organizacional efectiva, en una sociedad que vive desde los setentas un fuerte proceso de diferenciación social. En el juego político, los espectadores-representados ya no se sienten más identificados con los actores-representantes" (Abal, 2004:100).

Una vez establecido el hecho constitucional y legal de la representación, el problema investigado parte del desconocimiento de la ciudadanía sobre quiénes son sus representantes; del cuestionamiento de la eficacia de su trabajo legislativo prefiriendo acercarse a los medios de comunicación, y de la percepción ciudadana de desaprobación, desconfianza y corrupción en su desempeño, es decir, del descrédito de la institución legislativa (CESOP, 2003; GCE, 2012; IFE, 2014), que hace patente la baja calidad de la representación política y la necesaria rendición de cuentas como principales desafíos.

Por lo tanto, vinculados al problema, los objetivos que guían este trabajo buscan identificar fenómenos que afectan la calidad de la representación política en el actual contexto político de México, y se busca conocer el historial "cuestionable" de algunos diputados; la eficacia legislativa; y la confianza en los representantes y su institución. Con base en ello, se pretenden visualizar los desafíos que tendrán los diputados en funciones a fin de vincularse con la ciudadanía y que ésta conozca "quiénes son" los representantes de la LXIII Legislatura; que constate la eficacia de su trabajo legislativo y que recupere la confianza y credibilidad en esa institución.

La contribución de la investigación radica en identificar fuentes de información que coadyuven al conocimiento sobre quiénes son los representantes más allá de la identificación institucional, por ejemplo, de la Cámara de Diputados, que muestra el álbum fotográfico y el tipo de representación partidista que ejerce. Asimismo, contribuye y pone en tela de juicio antecedentes de algunos representantes en la Cámara de Diputados con "dudosa" probidad política; igualmente con la percepción de su bajo rendimiento legislativo; y con acciones que han contribuido al descrédito de esta institución afectando la transparencia y rendición de cuentas, y en consecuencia, la calidad de la representación política.

La investigación, es entonces, relevante por las graves condiciones políticas que tiene México y que hacen apremiante la accountability efectiva; es decir, el control de los ciudadanos-representados sobre los gobernantes-representantes, por varios mecanismos como los electorales, los ejercidos por organizaciones de la sociedad civil y por difusión de su actuar a través de los medios de comunicación masiva -prensa- (Gilas, 2010). 


\section{Metodología}

La investigación de carácter documental y descriptiva permitió caracterizar el objeto de estudio -la calidad de la representación política- a partir de fuentes de información de diversos documentos: los generados en instituciones oficiales (CESOP 2003; IFE, 2014; DOF, 2015); en trabajos de académicos que desarrollan labor investigativa en este campo (Béjar, 2006; Camacho, 2006; Alcántara, 2009); en encuestadoras de opinión pública relacionadas con el tema de estudio (GCE, 2012; Latinobarómetro, 2013; CIDE, 2015) y en medios de comunicación masiva -prensa- (Reforma, 2015; El Universal, 2015; Animal Político, 2015). La razón de incluir diarios es consecuencia de la falta de información sobre los representantes, que vincule su quehacer legislativo con la ciudadanía; sin embargo, el periodismo de investigación como agente de cambio ha ido supliendo esta labor, particularmente, por ser un medio de fácil acceso que busca "Formar, investigar, producir y difundir conocimiento en temas relacionados con la comunicación periodística " (CIDE, 2015).

Estos últimos medios de información sirvieron de sustento para una de las categorías que orientaron esta investigación con base en los objetivos señalados: conocer el historial "cuestionable" y de "dudosa" probidad política de algunos diputados (candidatos y electos) en la LXIII Legislatura. En un primer acercamiento se identificaron 9 constituyéndose en el 1.8\%, mientras que otra fuente documental identificó 129, el 25.8\% del total. De este tipo de fuente de información se identificó la preparación profesional para ejercer el cargo, 394 de 500 diputados electos siendo el $79 \%$. Las categorías de la eficacia del trabajo legislativo y de la confianza y credibilidad en la institución tuvo otro tratamiento y correspondió a información recopilada de fuentes oficiales y privadas, con la observación de que los datos corresponden a una parte del historial de la Cámara de Diputados en general y de los diputados en particular. Este punto es importante, debido al arrastre en la percepción negativa que se tiene de la Cámara Baja, a la vez que se constituye en el vínculo y articulación hacia los desafíos que tendrán que enfrentar los diputados en funciones, argumentos explicativos que llevaron a las conclusiones del presente trabajo.

\section{Resultados}

Las circunstancias políticas que está viviendo México implican un seguimiento permanente sobre quiénes son y qué hacen los 500 miembros que conforman la Cámara de Diputados (2015-2018) quienes tomaron posesión del cargo el primero de septiembre de 2015. Los representantes fueron elegidos bajo un sistema electoral mixto. La división geográfica-electoral de México se divide en 300 distritos electorales uninominales donde se eligen 300 representantes por mayoría simple 
y cinco circunscripciones plurinominales donde se eligen 200 por representación proporcional. En el proceso electoral federal del 7 de junio de 2015 , votaron 39.8 millones de electores. Comprendió la elección de cargos de elección popular en 17 entidades federativas con elecciones concurrentes para elegir en alguna de ellas, gobernador, diputados locales y alcaldes, sumado a la totalidad de la integración de la Cámara de Diputados con una tasa de participación electoral para ellos del $47.72 \%$ (INE, 2015). Finalizada la jornada electoral las inconformidades ante el TEPJF y sus respectivas resoluciones dieron por resultado que únicamente ocho partidos políticos tuvieran reconocimiento en la Cámara de Diputados, más un diputado independiente (véase tabla 1). La suma es de 498 por dos diputados aun en conflicto poselectoral en el TEPJF.

Los resultados de este trabajo se presentan conforme el problema planteado: en primer lugar, quiénes son los representantes de la LXIII Legislatura, cuyas fuentes de consulta se sustentaron en el periodismo de investigación; en segundo lugar, la rendición de cuentas y los desafíos de los representantes, resultados que se sustentan en datos que evidencian la eficacia del trabajo legislativo y en algunos porcentajes de la percepción ciudadana de la falta de confianza y descrédito de la institución legislativa. Estos dos últimos a manera de historial reciente del Congreso de la Unión proyectando con ellos, los retos de los diputados en funciones.

Tabla 1. Cámara de Diputados (2015-2018).

Composición partidista de la LXIII Legislatura

\begin{tabular}{|c|c|c|c|c|c|c|}
\hline \multirow{2}{*}{ Partidos políticos } & \multicolumn{2}{|c|}{ Mayoría relativa } & \multicolumn{2}{c|}{$\begin{array}{c}\text { Representación } \\
\text { proporcional }\end{array}$} & \multicolumn{2}{c|}{ Totales \% } \\
\hline PRI & 155 & 52.2 & 47 & 23.6 & 202 & 40.8 \\
\hline PAN & 55 & 18.4 & 53 & 26.6 & 108 & 21.7 \\
\hline PRD & 33 & 11.0 & 27 & 13.6 & 60 & 12.0 \\
\hline PVEM & 29 & 9.4 & 18 & 9.0 & 47 & 9.2 \\
\hline MORENA & 14 & 4.7 & 21 & 10.6 & 35 & 7.0 \\
\hline MC & 10 & 3.3 & 15 & 7.5 & 25 & 5.0 \\
\hline PANAL & 1 & 0.3 & 10 & 5.0 & 11 & 2.2 \\
\hline PES & 0 & 0.0 & 8 & 4.0 & 8 & 1.6 \\
\hline SIN PARTIDO & 1 & 0.3 & 0 & 0.0 & 1 & 0.2 \\
\hline INDEP. & 1 & 0.3 & 0 & 0.0 & 1 & 0.2 \\
\hline TOTALES & 299 & 100.0 & 199 & 100.0 & 498 & 100.0 \\
\hline
\end{tabular}

Fuente: Cámara de Diputados, H. Congreso de la Unión, LXIII Legislatura. Recuperado de: http://sitl.diputados.gob.mx/LXIII_leg/info_diputados.php 


\section{Conociendo a los representantes}

De acuerdo con Sánchez (2010), las teorías de la democracia representativa con carácter minimalista afirman que los representantes no tiene otro objetivo que no sea exclusivamente el de ganar el voto y en consecuencia, las elecciones; parte de esas premisas constituyen el sustento argumentativo de este apartado. Este sentido utilitarista hace a un lado ideales democráticos no logrando identificar los valores, aseveran sus críticos, puesto que los candidatos en cuestión pueden valerse de acciones que en el sentido popular, en la opinión pública, e incluso, por detractores políticos son peyorativos dado que el fin último es el de ganar, entre otros mencionamos: oportunismo, electoralismo, clientelismo, populismo, transfuguismo. Si bien Sánchez reconoce que éstas son ciertas formas de luchar por el voto -no ilegales- pero con reprobación pública, no tienen por qué ser condenables en una democracia moderna; y enseguida se pregunta: " ¿Cómo puede explicarse que la búsqueda del voto sea motivo de crítica política?" (2010, p. 114).

En su análisis reconoce que cuando un representante actúa por motivaciones electorales dispuesto a cambiar opiniones propias por acciones mayoritarias convenientes, es un oportunista, como podría ser el trásfuga, pero también advierte que no existe nada ilegal en el transfuguismo (aun trátese del disfrute máximo de tiempo posible de las rentas del poder), la ley de hecho, no lo castiga. Algo similar afirma del "electoralismo", como las medidas o anuncios destinados a conseguir el voto con base a cálculos electorales. Así, el partido puede desviar los compromisos adquiridos con sus votantes o puede guiarse por consideraciones de corto e inmediato plazo electoral con determinados grupos o partidos que le darán el apoyo; ambos aspectos implican que el representante y el partido puedan cambiar de posición ideológica sin mayores cuestionamientos. El clientelismo lo entiende como el uso de recursos públicos para dar recompensas materiales a los votantes que emitan su sufragio a favor de tal o cual partidocandidato. El populismo es otro de los fenómenos que lesiona la relación representantes- representados; no obstante, para Sánchez (2010) es cuestión de apreciación subjetiva puesto que ante posturas caducas y políticas fracasadas el líder populista y carismático es capaz de ofrecer soluciones a sus seguidores.

Con este preámbulo se presenta, resultado de la consulta de medios de comunicación masiva, una radiografía de la LXIII Legislatura que muestra más que datos, preocupación por el análisis que se realiza en tres rubros: el primero, vinculado a pendientes legales y señalamientos públicos vinculados con la justicia; el segundo, a la preparación académica para ejercer el cargo; y el tercero, a una práctica ya común en quehacer legislativo, el transfuguismo; rubros que sin duda alguna coadyuvan a conocer a nuestros representantes. 


\subsection{Pendientes legales y señalamientos públicos vinculados con la justicia}

Los datos refieren a un grupo de candidatos a diputados federales con antecedentes que pusieron en duda la probidad de su carrera política para lograr el triunfo y ocupar una curul en la Cámara de Diputados (véase tabla 2). Con la pregunta: ¿Los candidatos a diputados se han enfrentado alguna vez a la ley? ¿Por qué motivos? Los resultados de la encuesta ${ }^{3}$ únicamente determinaron que nueve casos eran de interés público en el contexto del proceso electoral constituyéndose en el $1.8 \%$ del total. Es llamativo que de acuerdo con este medio de información, los candidatos con pendientes legales pertenezcan sólo a la oposición partidista.

Tabla 2. Cámara de Diputados (2015-2018).

Composición partidista de la LXIII Legislatura

\begin{tabular}{|c|l|l|l|l|l|l|}
\hline $\begin{array}{c}\text { Presunto delito } \\
\begin{array}{c}\text { Presunto homicidio y } \\
\text { secuestro }\end{array}\end{array}$ & MC & & & & & Michoacán \\
\hline Presunto fraude & & PES & & & & Quintana roo \\
\hline Violencia domestica & & & PT & & & Sinaloa \\
\hline $\begin{array}{c}\text { Posible desvío de } \\
\text { fondos }\end{array}$ & & & & PAN & & Tlaxcala \\
\hline $\begin{array}{c}\text { Posible desvío de } \\
\text { recursos }\end{array}$ & MC & & & & & Michoacán \\
\hline $\begin{array}{c}\text { Posible desvío de } \\
\text { recursos }\end{array}$ & & & & & PRD & Puebla \\
\hline $\begin{array}{c}\text { Posible maltrato animal } \\
\text { Posible Tentativa de } \\
\text { homicidio }\end{array}$ & & & & & PRD & Puebla \\
\hline $\begin{array}{c}\text { Presunto adeudo hipo- } \\
\text { tecario }\end{array}$ & & & & & PANAL & Distrito federal \\
\hline
\end{tabular}

Fuente: Elaboración propia a partir de los datos del Diario Digital Animal Político (2015).

Recuperado de: http://www.animalpolitico.com/2015/06/malversacion-de-fondos-y-maltrato-animal-los-cargos-de-dos-virtuales-ganadores-a-diputados/.

3. Nota técnica: se buscó en 4,222 juzgados del país a los 9036 aspirantes, se acotaron a 720 que aparecían como demandados, demandantes o terceros involucrados. Criterio: "Buscar candidatos que hubiesen tramitado un amparo para protegerse de la acción de una Procuraduría, ante un posible delito penal..." Se encontraron 96. "Todos cotejados con la información pública de la Dirección General de Estadística Judicial del Consejo de la Judicatura Federal", quedaron sólo 9 casos. (Diario Digital Animal Político, 03/06/2015). 
Otra fuente de periodismo de investigación pública con datos diferentes, no sobre candidatos, sino sobre diputados electos y en funciones, cuya cifra se eleva considerablemente a 129, constituyéndose en el 25.8\% del total. Así tenemos que,

Una revisión de los perfiles de la próxima Legislatura deja ver personajes con señalamientos públicos por actos de corrupción, denuncias penales abiertas, procesos administrativos pendientes o acusaciones de nexos con la delincuencia. También casos en los que se presume uso indebido del cargo, ineficiencia en la función pública, improductividad legislativa o vínculos con poderes fácticos (una nueva telebancada), ello sin descartar a los que llegan a una curul sólo por su apellido, los llamados juniors de la política (Reforma, 2015).

Tabla 3. Señalamientos Públicos. Cámara de Diputados LXIII Legislatura

\begin{tabular}{|c|c|c|c|c|c|c|c|c|c|c|c|}
\hline $\begin{array}{c}\text { PARTI- } \\
\text { DO }\end{array}$ & $1^{*}$ & 2 & 3 & 4 & 5 & 6 & 7 & 8 & 9 & 10 & $\begin{array}{c}\text { TO- } \\
\text { TAL }\end{array}$ \\
\hline PRI & 4 & 5 & 4 & 2 & 1 & 3 & 2 & 1 & 3 & 1 & 26 \\
\hline $\begin{array}{c}\text { PRI- } \\
\text { PVEM }\end{array}$ & 5 & 2 & 2 & - & - & 3 & 4 & 2 & 10 & 1 & 29 \\
\hline PAN & 1 & 1 & 1 & 7 & 5 & 10 & 2 & 3 & - & - & 30 \\
\hline PRD & 5 & - & 3 & 3 & 2 & 1 & - & - & 1 & - & 15 \\
\hline PVEM & - & 1 & - & 1 & - & - & - & - & 2 & 2 & 6 \\
\hline MC & - & - & - & - & - & 2 & - & - & - & - & 2 \\
\hline PANAL & - & 3 & 1 & 1 & - & 2 & - & - & - & - & 7 \\
\hline TOTAL & 15 & 12 & 11 & 14 & 8 & 21 & 8 & 6 & 16 & 4 & $115^{* *}$ \\
\hline
\end{tabular}

Fuente: Elaboración propia a partir de los datos de: Diario Reforma (2015). El pasado los persigue.

Recuperado de: http://gruporeforma.reforma.com/interactivo/RevistaR/pasado_persigue/.

* Claves

1. Involucrados en procesos penales (15)

2. Con señalamientos de corrupción (12)

3. Nepotismo (11)

4. Polémico ejercicio de la función pública (14)

5. Presunto enriquecimiento ilícito (8)

6. Uso indebido del cargo (21)

7. Señalamientos públicos de nexos con el crimen (8)

8. Ex legisladores improductivos (6)

9. Juniors (16)

10. Telebancada (4)

** De los 115 diputados 56 son por mayoría relativa y 59 por representación proporcional. 14 
diputados en funciones son tránsfugas y se analizan más adelante.

Los datos de la tabla 3 tienen diferentes lecturas. Una de ellas, recae en las cifras de los partidos por sí mismos y otra es la sumatoria entre alianzas partidistas como es el caso del PRI y del PRI-PVEM, que implica el aumento de lo que se ha llamado "la representación política en negativo" de acuerdo a Sánchez (2010). Exclusivamente, se muestran las cifras, por cuestiones de espacio se omitieron los nombres, que no obstante, son del dominio público y pueden ser libremente consultados en las fuentes originales. Los nombres de los rubros en los que se agrupan a los representantes son claros por sí mismos, por lo que no se entrará en detalle para definir cada uno de ellos. En la tabla 3, los datos de la investigación original sitúan a 6 diputados dentro de lo que denomina "Izquierda Progresista", agrupación inexistente y donde los respectivos diputados pertenecen al PRD. En uno de los señalamientos por involucramiento en procesos penales está una diputada sin partido, que efectivamente así la registra la Dirección General de Apoyo Parlamentario de la Cámara de Diputados. También es pertinente puntualizar que algunos de los señalados son suplentes (que implica que quizás nunca ejercerán el cargo) mientras que otros sencillamente fueron sustituidos (aproximadamente diez); ello requiere otra investigación para un puntual seguimiento de los integrantes de la Cámara Baja y que quizá obedezca su sustitución a estos señalamientos públicos.

Es oportuno señalar que la difusión de estos datos se dieron con el carácter de periodismo de investigación, sin que a la fecha se haya conocido de alguna demanda de los representantes señalados por supuesta difamación o calumnia, incluso, se llega a la conclusión de que la búsqueda de lograr ocupar el cargo de representación obedece a la estrategia política y judicial de gozar, de acuerdo con las leyes mexicanas, de inmunidad parlamentaria o fuero constitucional, entendido éste como la prerrogativa que gozan "... senadores y diputados -así como de otros servidores públicos contemplados en la Constitución- que los exime de ser detenidos o presos, excepto en los casos que determinan las leyes, o procesados y juzgados sin previa autorización del órgano legislativo a que pertenecen: Parlamento, Congreso o Asamblea" (SIL, 28/08/2015).

\subsection{Preparación académica para ejercer el cargo}

Otro aspecto importante en el análisis de esta LXIII Legislatura es la preparación profesional del político elegido y en funciones. 
Tabla 4. Grado de Escolaridad. Cámara de Diputados LXIII Legislatura

\begin{tabular}{|c|c|c|}
\hline ESCOLARIDAD & TOTAL & $\%$ \\
\hline POSGRADO (Especialidad, Maestría, Doctorado) & 128 & 25.7 \\
\hline LICENCIATURA (Diversas carreras universitarias) & 266 & 53.4 \\
\hline SIN PREPARACIÓN UNIVERSITARIA (Normal, Preparatoria, Primaria) & 73 & 14.7 \\
\hline SIN DATOS VERIFICADOS & 31 & 6.2 \\
\hline TOTALES & 498 & 100.0 \\
\hline
\end{tabular}

Fuente: elaboración propia a partir de los datos de: El Universal. Periodismo de Investigación (2015) Cae nivel educativo en la Cámara de Diputados. Recuperado de: http://www.eluniversal.com.mx/articulo/periodismo-de-investigacion/2015/09/29/cae-nivel-educativo-en-camara-de-diputados

Dos puntos se señalan de los datos presentados en la tabla 4. El primero, refiere a que la Reforma político-electoral de 2013, dejó fuera de la norma el requisito mínimo de escolaridad para contender y ocupar un cargo en el Congreso de la Unión. El segundo, muestra que en la LXIII Legislatura sólo el $79 \%$ de los diputados tiene estudios superiores, lo que obliga a una comparación con Legislaturas anteriores: LX - 87\%; LXI - 90\% y LXII - 83\% (El Universal, 2015), mostrando que la preparación profesional de los diputados para ejercer el cargo en esta Legislatura está a la baja. A las cifras mostradas en la tabla 4 falta sumar a los diputados en funciones que a la fecha de la encuesta no habían proporcionado con veracidad su grado de escolaridad.

\subsection{Transfuguismo}

Los resultados del análisis de la LXIII Legislatura evidenció otro fenómeno (que ya se mencionó ligado al oportunismo) que se ha presentado de forma constante en la historia reciente en México y que es la clave para la transición democrática: el transfuguismo. Ríos (2009) reconoce que los tránsfugas priístas entre el periodo 1929-2000 han contribuido al cambio político del país al dejar su partido (PRI) para formar otro o para fortalecer ciertas instituciones partidistas aun con fines de poder político; es decir, en este país el transfuguismo se ha constituido en una forma de hacer política: "...cambiarse de partido ofrece la posibilidad de ganar el poder. La deslealtad o la disidencia partidistas comenzaron a ser rentables: presentarse con otras siglas a las elecciones y romper, por ende, con el viejo régimen que los formó fue para muchos atractivo tanto por el triunfo electoral como por la necesidad de canalizar su oposición" (Ríos, 2009, p. 252). Pero, independientemente de tal o cual explicación, éste implica una debilidad de 
la institución representativa porque los ciudadanos han votado por tal candidatopartido y éste pasa a otra bancada parlamentaria. Es entendible que se explique como una traición puesto que es la decisión del propio diputado quien determina el cambio de partido, bien, porque está inconforme con las políticas, la ideología o su actuar; o porque considera que sus expectativas personales de prebendas no se satisfacen dentro de ese partido. En aras de la libertad los representantes tienen el derecho de cambiar de partido, pero el transfuguismo electoral retribuido se ha convertido en México en uno de los problemas para la democracia actual por la fragmentación partidista, ideológica y política.

En la actual LXIII Legislatura, son 14 diputados los tránsfugas (véase tabla 5). Algunos de ellos incluso han cambiado en más de una ocasión de partido político, también los momentos han variado, antes de la elección o ya electos, hechos que van entre le ética, la corrupción y la legalidad porque los diputados tránsfugas no pierden derechos ni prerrogativas en su quehacer legislativo de acuerdo a la ley.

Tabla 4. Grado de Escolaridad. Cámara de Diputados LXIII Legislatura

\begin{tabular}{|c|c|c|c|c|c|c|c|c|}
\hline $\begin{array}{c}\text { Partidos } \\
\text { originarios }\end{array}$ & \multicolumn{7}{|c|}{ Partidos políticos a los que se incorporaron } & Total: 14 \\
\hline & PRI & PAN & PRD & PVEM & MORENA & MC & PANAL & PES \\
\hline PRI & & 1 & 1 & & & & 1 & 3 \\
\hline PAN & & & & 1 & & 1 & & \\
\hline PRD & 1 & & & & 1 & 2 & & \\
\hline PANAL & & 1 & & & & 1 & & \\
\hline
\end{tabular}

Fuente: elaboración propia con datos de: Diario Reforma (2015). El pasado los persigue. Recuperado de: http://gruporeforma.reforma.com/interactivo/RevistaR/pasado_persigue/.

No obstante, el tema es polémico y acorde a posturas radicales significa deslealtad al mandato representativo. Nuestro análisis rescata una consecuencia de este fenómeno vinculado a los resultados de las elecciones recientes en México (7 de junio de 2015), que pone en total evidencia la percepción ciudadana del "cambio" abrupto de ideología y adhesión partidista de los representantes que lesiona en gran medida la credibilidad de los partidos políticos. Al percibir la falta de adhesión partidista de los representantes anteponiendo sus intereses políticos y personales al cumplimiento del cargo para el que fueron elegidos, las candidaturas independientes se constituyeron en una alternativa para aquellos 
ciudadanos que no quieren votar por los partidos ante su "desprestigio". Un sondeo realizado después de las elecciones (CESOP, 2015) confirmó el apoyo a esta figura por el $70 \%$ de los entrevistados, mientras que el $65 \%$ opinó que es una manera de obligar a los partidos a tener mejores candidatos. Así, por primera vez en la historia reciente de México, gana una diputación un candidato independiente con el $42.45 \%$ de los votos (INE, 2015), quien previamente había renunciado al partido que lo formó políticamente ${ }^{4}$.

\section{Rendición de cuentas: los desafíos de los representantes}

A pesar de los indicadores de crisis de la representación política ante el distanciamiento entre los representantes y sus representados, o en su defecto, por acciones de los primeros ajenas al beneficio popular, existen argumentos que de alguna forma tratan de justificar tales acciones "independientes". El punto de partida es el propio proceso electoral. Cuando los ciudadanos votaron y eligieron propiciándoles el triunfo electoral, ellos apostaron por paquetes completos de acciones y medidas políticas con sustento en un determinado programa (que se entiende fue diferenciado de "otros"). "La naturaleza ideológica de la representación política exige que el representante tenga cierta autonomía. El representante no puede actuar sólo en función de la preferencias de los representados en cada momento del tiempo, pues semejante servidumbre haría peligrar la 'integridad' que se espera de quien ejerce la representación" (Sánchez, 2010, 91).

Bajo esta perspectiva, parte de las exigencias de la democracia representativa es dejar en libertad a los representantes para que ejerzan su proyecto político, como se espera sucederá en la LXIII Legislatura con los representantes-diputados. Sin embargo, no debe perderse de vista que actualmente en el juego democrático también se exige el control de los políticos como un aspecto fundamental: es decir, la rendición de cuentas. El vínculo estrecho entre democracia y rendición de cuentas, se sustenta en que "... la democracia debe generar determinados espacios en los que los gobernantes puedan ser influenciados por la gente para lo cual debe haber un mínimo grado de poder compartido" (Alcántara, 2012, p. 192). El nivel efectivo de la rendición de cuentas está determinado por ese mínimo grado.

\footnotetext{
4. Fue histórico el número de candidatos independientes que ganaron: un gobernador, un diputado federal, un diputado local y tres presidentes municipales (INE, 2015).
} 
De acuerdo con Alcántara (2012), en cada sociedad existen diferentes mecanismos que permiten esa rendición de cuentas. Así, de forma horizontal los mecanismos de control son de origen parlamentario, jurisdiccional y societal como revocación de mandato o iniciativa legislativa; de forma vertical la rendición de cuentas se vigila en los procesos electorales; y en ese universo de información continua, los medios de comunicación masiva y organizaciones de la sociedad civil generan instancias evaluadoras de la actividad política. Siguiendo a este autor, dos puntos más se suman a la rendición de cuentas: uno, se refiere a la acción escrutadora de la opinión pública que sanciona la actuación de los políticos en términos de control social, de disminución de su popularidad y del deterioro de su reputación; el otro, indica la probabilidad de que la política se judicialice cuando las instituciones son incompetentes para llevar a cabo la rendición de cuentas de los políticos. En la práctica y con fines operativos,

La rendición de cuentas tiene dos dimensiones, una que se basa en la obligación de los políticos de responder e informar sobre sus actos para lo cual la transparencia y la justificación de los mismos se convierten en aspectos fundamentales; y la segunda tiene que ver con la existencia de agencias controladoras que tengan capacidad de imponer sanciones a los políticos que hubieran violado sus obligaciones públicas (Alcántara, 2012, p. 193).

Con estas premisas sobre la rendición de cuentas se presenta el resultado de la consulta de obras de intelectuales especialistas en la temática, de medios académicos y de encuestadoras oficiales y privadas, un análisis del Congreso de la Unión que muestra información, en tres rubros: el primero vinculado a datos que evidencian la eficacia del trabajo legislativo (con un breve histórico); el segundo, con porcentajes de la percepción ciudadana sobre la confianza en la institución que conforma el poder legislativo en México; y el tercero con los desafíos que enfrentan los diputados en funciones.

\subsection{Eficacia del trabajo legislativo}

Los diputados federales en México tienen entre otras funciones, la producción legislativa, la aprobación anual del Presupuesto de Egresos de la Federación, la revisión de la Cuenta Pública y las acciones de procedencia penal hacia funcionarios cuando hubiere lugar a ello (Artículo 74, CPEUM). La eficacia del trabajo legislativo se entiende como la producción y cumplimiento de los miembros de la Cámara Baja de las tareas que por mandato constitucional deben 
realizar. En 2003 el $\mathrm{CESOP}^{5}$ presentó datos sobre la percepción ciudadana de la eficacia del trabajo de los diputados federales arrojando que seis de cada 10 lo consideraron "malo-inadecuado"; dos de cada 10 lo valoraron como "muy eficiente"; mientras que siete de 10 dijeron que los legisladores "trabajan poco"; y uno de 10 que "trabajan mucho". Por su parte, en 2012 se difunden datos ${ }^{6}$ sobre la calidad del trabajo de los diputados (incluidos senadores) arrojando que $34.1 \%$ considera que sólo buscan su beneficio personal; $29.1 \%$, que no son trabajadores pues hacen poco y cobran mucho, y sólo 16.8 y $13.7 \%$, respectivamente, los ven como representantes del pueblo y como servidores públicos.

Esta percepción se constata en la LXIII Legislatura (2015-2018). Es del conocimiento público que uno de los principales problemas de México son las acciones violatorias y la consecuente impunidad, lacra que también atrapa a los legisladores. A raíz de una serie de hechos recientes que muestran a la luz pública acciones violatorias a la ley, Zuckermann (2013) a través de los medios denuncia que los legisladores, los señores encargados de hacer las leyes, no las cumplen, ello por el desacato hacia el TEPJF quien ordenó a la Cámara de Diputados nombrar de inmediato al consejero faltante del IFE, obedeciendo la ley once meses después. Carbonell (2014) en lo que llama irresponsabilidad legislativa hace recuento de una serie de pendientes sin resolver (y con fechas vencidas) que tienen los miembros del Congreso de la Unión, pudiendo acudir la instancia correspondiente al máximo tribunal del país, Suprema Corte de Justicia de la Nación (SCJN) para demandar controversia constitucional y obligarlos al cumplimiento del trabajo, pero, nada sucede, porque, afirma Zuckermann, "Es evidente: a nuestros representantes no les da vergüenza violar la ley" (2013, p. 2), pero aún más, para la irresponsabilidad legislativa, "La vía legal existe, falta voluntad política para activarla" (Carbonell 2014, p. 3).

Enseguida se presenta la labor investigativa de un grupo de académicos quienes se dieron a la tarea de hacer un recuento histórico reciente de la eficacia del trabajo legislativo, es decir, del cumplimiento de una de las funciones que deben realizar los integrantes del Congreso, no únicamente hacer las leyes sino cumplirlas. "El Violómetro Constitucional es un instrumento digital que ofrece datos cronológicos y legislativos puntuales para medir en tiempo real,

\footnotetext{
5. Nota metodológica: El CESOP de la Cámara de Diputados retomo datos de diferentes fuentes. Sobre la valoración del trabajo legislativo: GEA-BGC; encuestas aplicadas entre 01/08/2002-01/08/2003; sobre la eficiencia: Ipsos-Bimsa, encuesta telefónica nacional en 2003; sobre el trabajo de mucho-poco es un promedio histórico entre 22/04/1998-11/04/2002, BGC-Ulises Beltrán Asocs.
}

6. Tomado de ADN Político (2012) Encuesta: Mexicanos desdeñan a los diputados y senadores, 26/08/2012. Nota metodológica: encuesta telefónica a 800 mexicanos, 22/08/2012. 
las violaciones constitucionales en que incurre el Congreso de la Unión al no cumplir con sus obligaciones legislativas dentro de los plazos establecidos en la ley" (CIDE, 2015). Lo que han denominado "El verdadero reloj legislativo" (véase tabla 6) registra tres momentos en el quehacer de los legisladores y que miden en consecuencia su eficacia legislativa: Violaciones actuales de diputados y senadores; Obligaciones en curso y Violaciones pasadas. El registro que realiza el Violómetro Constitucional se actualiza en cada segundo, por lo que un instrumento pertinente para conocer la eficacia del trabajo de los legisladores al día.

Tabla 4. Grado de Escolaridad. Cámara de Diputados LXIII Legislatura

\begin{tabular}{|c|c|c|c|c|c|c|}
\hline Tipo & \multicolumn{7}{|c|}{ Legislaturas responsables } \\
\hline & LVIII & LIX & LX & LXI & LXII & LXIII \\
\hline Violaciones actuales & & & 2 & 4 & 18 & 18 \\
\hline Obligaciones en curso & & & & & 4 & 4 \\
\hline Violaciones pasadas & 1 & 1 & 8 & 11 & 29 & 2 \\
\hline Totales & 1 & 1 & 10 & 15 & 51 & 24 \\
\hline
\end{tabular}

Fuente: elaboración propia con datos del Violómetro Constitucional. El verdadero reloj legislativo (2015). CIDE. Recuperado de http://periodismocide.org/eventos/violometro/

Los datos sobre la actual Legislatura LXIII en parte corresponden al atraso legislativo que dejó la anterior Legislatura, pero que al momento de asumir el cargo son responsables. Los temas sobre la legislación pendiente son diversos (energía, transparencia, derechos y garantías, competencia económica, etcétera), todos importantes para la conducción de la nación. En su momento, quien fue legislador en varias ocasiones y presidente de la Cámara de Diputados afirmó: "De ahí que antes que concluya el periodo ordinario...manifestáramos nuestra disposición a efectuar los periodos extraordinarios que fueran necesarios para desahogar las leyes secundarias... y darles viabilidad en un tiempo razonable... [se busca] imprimir eficacia al trabajo legislativo..." (Beltrones, 2014).

Para algunos especialistas parte de la solución para elevar la eficacia de su trabajo sería fortalecer al poder legislativo con la reelección legislativa inmediata "...si de verdad queremos contar con legisladores profesionales, expertos y responsables ante los ciudadanos" (Jaimes, 2011, p. 59). En otra lectura, más bien lo que se aprecia es la conveniencia de los tiempos políticos y de los intereses de los actores que conducen al país, éstos son los que en última instancia determinan la discusión y aprobación de leyes, es decir, el reloj legislativo. 


\subsection{Percepción ciudadana sobre la confianza}

Un factor esencial de las democracias representativas es la confianza de la ciudadanía en las instituciones. De forma constante instituciones internacionales y nacionales realizan sondeos de opinión sobre el tema que nos ocupa articulándose con otros fenómenos de índole político-social, estudios que toman sentido en análisis comparativos con otros países. La propia Cámara de Diputados a través del CESOP (2003)7 publicó un estudio denominado "La Cámara de Diputados en la opinión pública" con el fin de autoevaluarse. Los resultados son desalentadores en tanto que muestran un bajo nivel de confianza y aprobación de su trabajo, sumado a que consideran que no representan sus intereses, es decir, muestran la poca confianza y aprobación que tiene el Congreso de la Unión ante la ciudadanía. Sólo 4 de cada 100 ciudadanos afirmó tener "mucha confianza" en la Cámara de Diputados y en el extremo el 58\% afirmó tener "total desconfianza". En la Encuesta Nacional 2011 (GCE, 2011) ante la pregunta expresa: ¿Qué tanta confianza tiene usted en las siguientes instituciones? de 21 en total, el Congreso de la Unión (diputados y senadores) tuvieron el tercer más alto porcentaje de desconfianza $13.7 \%$, seguido de la policía 13.8\% y los partidos políticos 14.2\%, incluso por arriba de la confianza en los medios de comunicación (8.5\%). Por su parte Mitofsky $(2014)^{9}$ quien anualmente (desde 2004) realiza un seguimiento sobre la confianza en diferentes instituciones en México, presentó un concentrado de datos que exhiben el grado de confianza hacia los diputados federales con un promedio de 5.60, pero mostrando que en los 11 años de investigación las calificaciones más bajas siempre han sido para los diputados (5.4) y los partidos políticos (5.1) cifras que impactan la encuesta de marzo de 2014.

Transparency International (2013) publicó datos de la percepción ciudadana sobre la corrupción, lacra que es alarmante en el mundo entero ${ }^{10}$. Para México, éstos se vinculan a la falta de confianza y al descrédito de las instituciones vinculadas a la

7. Ficha técnica de CESOP (2003): Se conjuntaron datos de las principales empresas encuestadoras de México: Mitofsky, Parametría, BGC, Ipsos-Bimsa, Reforma, GEA-ISA realizadas entre 1999-2003.

8. Nota metodológica: Aplicada a adultos mayores de 18 años, 3000 encuestas en todo el territorio mexicano, nivel de confianza 95\% margen de error \pm 1.79\%, levantada entre 19-25 septiembre de 2011.

9. Nota metodológica de Mitofsky: 1000 mexicanos mayores de 18 años con credencial para votar residentes en territorio nacional en viviendas particulares, 95 de 100 veces el error no sobrepasa el $\pm 3.1 \%$ en las estimaciones; $7-10$ de febrero de 2014

10. Transparency International (2013) mide la percepción de la corrupción hacia el sector público. La información se recolecta por encuestas y a través de instituciones nacionales e internacionales. Para México: la muestra fue de 1052 personas citadinas con el método de entrevista cara a cara con un cuestionario de 12 preguntas. 
democracia y al quehacer legislativo mostrando que de todos los países encuestados los partidos políticos en México están considerados como una de las instituciones más corruptas/o extremadamente corruptas con un $91 \%$, lo mismo ocurre con Parlamento/Legislatura con $83 \%$; a este porcentaje se suma la ineficacia que se percibe del gobierno en la lucha contra la corrupción 73\%, dado que la percepción de la corrupción en los funcionarios públicos también es alta, $87 \%$, y del poder judicial del 80\%, poder que se supone debe castigar el acto. En 2013 ocupó el sitio 106 de los 177 encuestados; para 2014, las cifras no variaron mucho respecto a los indicadores señalados ocupando el lugar 103 de los 175 encuestados.

De forma más concreta hacia la institución parlamentaria en México, cifras semejantes reporta el Latinobarómetro (2013): sólo el 4.7\% de los ciudadanos tiene mucha confianza en el Congreso, $23.8 \%$ algo de confianza, 34.8\% poca confianza y el $31.6 \%$ ninguna confianza, datos que denotan falta de credibilidad y confianza hacia los representantes, quienes van perdiendo fuerza como símbolos nacionales cercanos al pueblo ${ }^{11}$.

Otro punto que se suma a este análisis es el estudio realizado por Alcántara $(2009)^{12}$ sobre la Cámara de Diputados, los representantes y la confianza que ellos tienen hacia las instituciones públicas, por ejemplo: "... con relación a los propios partidos políticos se refleja un profundo síndrome bipolar, ya que los propios políticos, elegidos en el seno de los partidos políticos, desconfían de los mismos" (2009, p. 331), la confianza en promedio es del 5,6\%. Algo similar ocurre con la confianza en la independencia del poder judicial (3,07\%) por parte de los partidos, mostrando que "La baja tasa de confianza en instituciones centrales del Estado de derecho... confiere a la democracia... altas dosis de precariedad" (Alcántara, 2009, p. 334). En suma, para Alcántara la inseguridad ciudadana y el mal funcionamiento y desconfianza en las instituciones básicas vislumbran una vida política poco estable para México.

\subsection{Desafíos que enfrentan los diputados}

Estrechamente vinculados con los resultados que se han presentado, se pone en la mira los desafíos que los diputados en funciones de la LXIII Legislatura deben

11. Ficha técnica para México: Muestra probabilística en tres etapas, por cuotas en la etapa final, 1200 encuestados, intervalos de confianza del 95\%, error muestral \pm 2.8 , Latinobarómetro (2013).

12. Nota metodológica: Entrevistas personalizadas mediante cuestionario cerrado a 128 diputados de todos los partidos con un nivel de confianza del $95.5 \%$ y un error teórico de $\pm 7,13$ para el conjunto de la muestra, aplicadas octubre-diciembre 2006. (Alcántara, 2009: 323). 
alcanzar por el bienestar de la ciudadanía y por la recuperación de la credibilidad de esa institución. El punto esencial es la rendición de cuentas. Políticamente, su impacto puede recaer en lo individual, en el político y el representante, pero también en el partido que al verse afectado con cuestiones de deshonestidad, falta de transparencia y corrupción, se ve obligado a dirigirse a la opinión pública. Una sólida maquinaria partidista puede salvar cabezas de políticos seriamente dañados, pero el perjuicio puede permanecer y aumentar en el colectivo social con la desconfianza y el desprestigio social que traerá a futuro costes políticos y electorales (Alcántara, 2012). Sus posibles consecuencias pueden ir desde la derrota electoral, el desafuero político, el juicio político, el desprestigio y fin el de la carrera política. En este sentido, a pesar de reconocerse que la rendición de cuentas es un importante componente democrático-electoral, Alcántara afirma que "...las elecciones se están convirtiendo en un mecanismo dudoso de rendición de cuentas siendo más bien un instrumento que queda recluido a la función de generar mandato" (2012, p. 97).

Debe señalarse que el ideal representativo se empaña con la negativa rendición de cuentas que desafortunadamente en México se ha presentado de forma constante, incluso, a pesar de nuevas legislaciones como la Ley General de Transparencia y Acceso a la Información Pública (DOF, 2015) que exige a los integrantes del poder legislativo la rendición de cuentas, así como las modificaciones constitucionales en materia de combate a la corrupción (DOF, 2015) y la Ley Federal de Responsabilidades Administrativas de los Servidores Públicos en el Articulo 36 sobre la declaración patrimonial. A estas legislaciones se señalan las instituciones independientes para la rendición de cuentas y transparencia: el Instituto Nacional Electoral, la Comisión Nacional de Derechos Humanos y la Auditoria Superior de la Federación. "La historia del diseño y desarrollo institucional de estos tres organismos por un lado demuestra que la descentralización de la autoridad -más que la centralización del poder- puede ser más efectiva para estimular la innovación en políticas públicas y en la delegación efectiva" (Ackerman, 2007: 19).

De este modo, vinculado a los procesos electorales, la rendición de cuentas es una obligación de los partidos políticos ante el INE, instancia que tiene la facultad de revisar, origen monto y destino del financiamiento de los partidos bajo el Reglamento de Fiscalización resultado de la reforma político-electoral de 2013. No obstante, en la página oficial del Instituto, el dato más detallado es la elección 2009-2010 donde señala las sanciones monetarias impuestas a ocho partidos derivadas de los informes de pre-campañas y campañas por más de 32 millones de pesos (INE, 2015). En las últimas elecciones federales de junio 2015, el Consejo General del INE aprobó a los 10 partidos políticos nacionales multas por más 
de 393 mdp, siendo el PVEM el más sancionado con 72.9 millones, las razones y violaciones a la norma son varias, pero finalmente se enfoca a la opaca rendición de cuentas (INE, 2015).

Finalmente, siguiendo Abal (2004) quien afirma que "El ciudadano medio visualiza lo político como algo distante y remoto, un mundo sucio plagado de comportamientos egoístas, estratégicos e hipócritas en el que él no tiene ninguna capacidad de acción" (p. 106). Ahí se percibe que los lastres, el uso y abuso del poder, incluso, la intelectualidad tecnopolítica (Alcántara, 2012, p. 191) no es un factor que frene la representación política en negativo.

\section{Conclusiones}

Se han identificado ciertos fenómenos que afectan la calidad de la representación política en México, particularmente en la Cámara de Diputados. Se concluye que gran parte están ligados a los procesos electorales que tienen su sustento en una crítica mirada retrospectiva que ha constatado el deshonesto actuar de algunos diputados -quiénes son realmente- así como el cuestionamiento sobre qué han hecho los representantes: si realmente han defendido los intereses del pueblo o han usado el cargo político en beneficio propio, partidista, de clase política, económica o incluso, con intereses fuera de la ley; hechos que en consecuencia, evidencian la imagen dañada y de descrédito que sobre ellos percibe la ciudadanía en general.

El cuestionamiento de la eficacia de su trabajo legislativo y la confianza en sus instituciones abre la brecha entre representantes y representados. Los datos presentados de las diferentes encuestas constituyen únicamente indicadores que buscan dar explicaciones al problema planteado. Las categorías, los espacios y periodos utilizados también se entiende que su interpretación corresponde a momentos coyunturales del movimiento de la sociedad. Pero lo que se debe señalar, es que en la mayoría de los rubros encuestados lleva implícito el uso y abuso del poder, fenómeno que se liga a la corrupción, el enriquecimiento y al ejercicio indebido del cargo, condiciones que dañan la calidad de la representación política.

Al respecto, y acorde a los datos que se ha presentado, los propios diputados del Congreso mexicano (CESOP, 2003) reconocen el problema y se hacen escuchar: la baja calidad de la representación política, la falta de confianza y el descrito de la institución parlamentaria no es privativa de México, en otras latitudes también existe alejamiento y desencanto de la política; en este país, el dominio que ejerce el poder ejecutivo disminuye la percepción de los beneficios del poder legislativo, 
genera mala imagen parlamentaria, la ciudadanía no conoce la estructura y funciones de la Cámara, aunado a que la cobertura mediática no privilegia logros sino desacuerdos y casos aislados de legisladores no representativos.

Se reconoce el impacto en la rendición de cuentas tienen los medios de comunicación masiva en este siglo XXI de inmediatez por las nuevas tecnologías de información. Sobre esto coincidimos con Alcántara (2012) quien distingue los espacios que generan los medios ligados a los escándalos políticos de la información generada por el periodismo de investigación ligado a la ética y al profesionalismo que contribuye a crear espacios más democráticos y transparentes para la rendición de cuentas.

El desafío actual de los representantes y de los partidos políticos de la LXIII Legislatura es generar acciones transparentes que favorezca la credibilidad en ellos y en nuestras instituciones. Debe entenderse que sustentada en un ideal democrático, la calidad de la representación política debe renovarse en el sentido de exigir a los representantes electos y en funciones regresar periódicamente a la rendición de cuentas ante sus representados, explicar y fundamentar las decisiones tomadas, efectivamente, en el bien de la nación, pero, también y esencialmente, en beneficio de la ciudadanía. Estas acciones políticas contrarrestaría en cierta medida el descredito de las instituciones representativas y el malestar de la sociedad civil. Pero, también una representación política de calidad no sólo exige la rendición de cuentas y acciones transparentes de los representantes, también la participación fuerte y sustantiva de los representados, de tal forma que luchen y generen espacios de participación política para hacerse escuchar no únicamente en los procesos electorales, sino en demandas permanentes hacia la fiscalización y acompañamiento del actuar sustantivo de los representantes.

\section{Referencias}

Abal, J. (2004). La muerte y la resurrección de la representación política, Argentina: Fondo de Cultura Económica.

Ackerman, J. M. (2007). Organismos autónomos y democracia. El caso de México, México: Siglo XXI, IIJ-UNAM.

Albala, A., Vieira, S. (2014). Crisis de los partidos en América Latina? El papel de los partidos políticos latinoamericanos en el escenario reciente, Política, 52(1), 145-170. 
Alcántara, M. (2009). Democracia y representación política en la Cámara de Diputados mexicana. En Alcántara Sáenz, M. y Hernández Norzagaray E. (Comps.) México el nuevo escenario político ante el bicentenario, España: Ediciones USAL.

Alcántara, M. (2012). El oficio de político, Madrid: Tecnos.

Béjar, L. (2006). Los partidos en el Congreso de la Unión. La representación parlamentaria después de la alternancia, UNAM/Gernika, México.

Béjar Algazi L. (2009). ¿Qué pasa con la representación en América Latina?, México: M. A. Porrúa.

Beltrones, M. F. (2014) Productividad y eficacia legislativa, El Universal, 26/05/2014.

Bobbio, N. (1998). Representación e Intereses. En Fernández Santillán, J., Norberto Bobbio: el filósofo y la política, México: Fondo de Cultura Económica.

Camacho, J. L. (2006). El Congreso Mexicano, México: M.A. Porrúa.

Cámara de Diputados, H. Congreso de la Unión, LXIII Legislatura. Recuperado de: http://sitl.diputados.gob.mx/LXIII_leg/info_diputados.php.

Carbonell. M. (2014). La irresponsabilidad política, Periodismo CIDE, Recuperado de http://periodismocide.org/eventos/violometro/

Centro de Estudios Sociales y de Opinión Pública (2003). La Cámara de Diputados en la Opinión Pública, CESOP, LIX Legislatura: Cámara de Diputados.

Centro de Investigación y Docencia Económicas (2015). Violómetro Constitucional. El verdadero reloj legislativo, Periodismo CIDE. Recuperado de: http:// periodismocide.org/eventos/violometro/

Cepeda, J. A. (2004). Cuadernos del seguimiento ciudadano al poder legislativo en México. La LVIII Legislatura en la Cámara de Diputados. Diagnóstico de un camino hacia la consolidación democrática, México: Fundar Centro de Análisis e Investigación. 
Consulta Mitofsky. The poll reference (2014). México: Confianza en instituciones. Calificación Confianza en instituciones (2004-2014). Recuperado de www. consulta.mx

Dahl, R. (1989). La poliarquía, Madrid: Tecnos.

Diario Digital Animal Político (2015). Pendientes legales de los candidatos a diputados federales. Recuperado de: http://www.animalpolitico.com/2015/06/ malversacion-de-fondos-y-maltrato-animal-los-cargos-de-dos-virtualesganadores-a-diputados/

Diario Oficial de la Federación (2015). Secretaría de Gobernación, DECRETO por el que se expide la Ley General de Transparencia y Acceso a la Información Pública. Recuperado de: http://www.dof.gob.mx/nota detalle.php?codigo $=5391143 \&$ fecha $=04 / 05 / 2015$

Diario Oficial de la Federación (2015). Secretaría de Gobernación, DECRETO por el que se reforman, adicionan y derogan diversas disposiciones de la Constitución Política de los Estados Unidos Mexicanos, en materia de combate a la corrupción. Recuperado de: http://dof.gob.mx/nota_detalle. php? codigo $=5394003 \&$ fecha $=27 / 05 / 2015$

Diario Reforma (2015). El pasado los persigue. Recuperado de: http:// gruporeforma.reforma.com/interactivo/RevistaR/pasado_persigue/

Díaz, E. (2006) Los partidos en Congreso de la Unión. La representación parlamentaria después de la alternancia, México: UNAM-Gernika.

Dworak F. (Coord.) (2003). El legislador a examen. El debate sobre la reelección legislativa en México, México: Cámara de Diputados-FCE.

El Universal (2015). Observatorio del Congreso. Recuperado de: http://data. eluniversal.com.mx/observatorio-congreso/. 07/09/2015.

Gabinete de Comunicación Estratégica. Encuesta Nacional 2011. Política. Vivienda. 03/10/2011. Recuperado de http://gabinete.mx/descargas/ encuesta_nacional/2011ps/encuesta2dolev_web.pdf 
Gabinete de Comunicación Estratégica. Encuesta Nacional (2012). Encuesta telefónica realizada el 22 de agosto. Recuperado de http:/ / www.adnpolitico. com/encuestas/2012/08/26/3-de-cada-4-mexicanos-no-quieren-serdiputados-ni-senadores

Flores, A. (2004). La relación Ejecutivo-Legislativo en México después del 2 de julio del 2000 en Escobedo, Juan Francisco, Editor, (2004), Representación Política y toma de decisiones, México: Fundación Konrad Adenauer y FIDAC.

Franzé, J. (1996). El discurso del malestar civil: la crisis de la política como crisis de lo político, en Porras Nadales, A., (Coord.) El debate sobre la crisis de la representación política, Madrid: Tecnos.

Gilas, M. (2010). Calidad de la democracia y representación, en Revista Legislativa de Estudios Sociales y Opinión Pública, 3(5),155-181.

Gimate-Welsh, A. y Rodríguez Carrillo, J. M. (2008). Votos y preferencias en un gobierno dividido. En Espinoza Toledo, R. y Weldon, F. (Coord.). Para qué sirve el Poder Legislativo, México: UAM, M. A. Porrúa.

Gimate-Welsh, A. y Rodríguez Carrillo, J. M. (2015). Construcción de coaliciones y producción legislativa en el gobierno de Felipe Calderón. En Hernández de Gante, A. Gimate-Welsh, A. y Moreno Sánchez, C. (Coord.). La revitalización del Poder Legislativo en el gobierno calderonista, México: Gernika.

Gómez, A. (2011). Los partidos políticos, Reflexión Política, 13(26), 4-15.

Hernández, A. (2008). Reflexiones sobre la crisis de la representación política en México, México: Montiel \& Soriano Editores.

Instituto Federal Electoral (2014). Informe país sobre la calidad de la ciudadanía en México, México: IFE-COLMEX.

Instituto Nacional Electoral (2015). Sanciones Impuestas por Año. Recuperado de: http://www.ine.mx/archivos3/portal/historico/contenido/Sanciones_Impuestas/ 
Jaimes, D. A. (2011) ¿Cómo fortalecer el poder legislativo federal en México?: el caso de la reelección inmediata de los miembros de Congreso, en Revista Mexicana de Derecho Constitucional, (25), julio-diciembre, 59-99.

Latinobarómetro (2013). Banco de Datos en Línea, Informe Anual, Santiago de Chile. Recuperado de: http://www.latinobarometro.org/documentos/ LATBD_INFORME_LB_2013.pdf.

Ley General de Transparencia y Acceso a la Información Pública, Cámara de Diputados, H. Congreso de la Unión, (DOF, 04/05/2015).

Ley Federal de Responsabilidades Administrativas de los Servidores Públicos, Cámara de Diputados, H. Congreso de la Unión, (DOF, 14/07/2014).

Levine, D. y Molina, J. E. (2007). La calidad de la democracia en América Latina: una visión comparada, en América Latina Hoy, (45), 17-46.

Mainwaring, S., Bejarano, A. M. y Pizarro, E. (Coord.) (2008). La crisis de la representación democrática en los países andinos, Colombia: Editorial Norma.

Novaro, M. (2000). Representación y liderazgo en las democracias contemporáneas, Buenos Aires: Homo Sapiens Ediciones.

O’Donnell, G. (2007). Disonancias. Críticas democráticas a la democracia, Buenos Aires: Prometeo.

Pardo, R. (2008). Restricciones al dialogo democrático en Colombia: La Dispersión de partidos, la violencia y el sistema presidencialista.. Ánfora, 15(24), 1-10. Recuperado de http:/ / www.redalyc.org/articulo.oa?id=357834342011

Pérez, G. y Martínez, A. (Comps.) (2000). La Cámara de Diputados en México, México: FLACSO.

Pitkin, H. (1985). El concepto de representación, Madrid: Centro de Estudios Constitucionales.

Ríos, L. E. (2009). El transfuguismo electoral. Un debate constitucional en México, Cuestiones Constitucionales. Revista Mexicana de Derecho Constitucional (21), 251-294. 
Sánchez, I. (2010). Más democracia, menos liberalismo, Madrid: Katz Editores.

Santamaría, J. (1998). El papel del parlamento durante la consolidación de la democracia y después, Revista Mexicana de Sociología, 60(2), 3-20.

Sistema de Información Legislativa (2015). Fuero constitucional, Secretaría de Gobernación, Gobierno Federal. Recuperado de: http://sil.gobernacion. gob.mx/Glosario/definicionpop.php? ID= 106

Transparency International (2013). Global Corruption Barometer 2013. Recuperado de https://www.transparency.org/gcb2013/report

Tuckman, J. (2013). México, democracia interrumpida, México: Debate.

Valencia Escamilla, L. (2007) La representación parlamentaria. Un recorrido histórico por la teoría política, México: Cámara de Diputados, UAM, M.A. Porrúa.

Zuckermann, L. (2013). De cómo los diputados violan la ley y no pasa nada. Excélsior, 18/07/2013, p. 6. 